\title{
PCV cap proteins fused with calreticulin expressed into polymers in Escherichia coli with high immunogenicity in mice
}

Chang Liu ${ }^{1 \dagger}$, Yunchao Liu ${ }^{1 \dagger}$, Hua Feng ${ }^{1}$, Baolei Zhao ${ }^{2}$, Yumei Chen ${ }^{3}$, Huimin Huang ${ }^{2}$, Pan Wang ${ }^{1}$, Ruiguang Deng ${ }^{1}$ and Gaiping Zhang ${ }^{1,2,3^{*}}$

\begin{abstract}
Background: Porcine circovirus type 2 (PCV2) is the main causative agent of porcine circovirus diseases (PCVDs) which causes huge yearly economic losses in the swine industry. Capsid protein (Cap) is the major structural protein of PCV2 that can induce a protective immune response. Therefore, developing a novel and safe subunit vaccine against PCV2 infection is needed.

Results: In this study, the Cap gene was bound to the truncated calreticulin (CRT) (120-250 aa/120-308 aa) at the $\mathrm{N} / \mathrm{C}$ terminal, and then the CRT-Cap fusion genes were expressed in Escherichia coli (E.coli). The size-exclusion chromatography and dynamic light scattering (DLS) data showed that the purified recombinant CRT-Cap fusion protein (rP5F) existed in the form of polymers. Immunization with rP5F stimulated high levels of PCV2 specific antibody and neutralization antibody in mice, which were almost identical to those induced by the commercial subunit and inactivated vaccines. The lymphocyte proliferation and cytokine secretion were also detected in rP5F immunized mice. According to the results of PCV2-challenge experiment, the virus loads significantly decreased in mice immunized with rP5F. The data obtained in the current study revealed that rP5F had the potential to be a subunit vaccine candidate against PCV2 in the future.
\end{abstract}

Conclusions: We have successfully expressed Cap-CRT fusion proteins in E.coli and optimized rP5F could form into immunogenic polymers. Mice immunized with rP5F efficiently induced humoral and part of cellular immune responses and decreased the virus content against PCV2-challenge, which suggested that rF5P could be a potential subunit vaccine candidate.

Keywords: Porcine circovirus type 2, CRT-cap fusion protein, Escherichia coli, Polymers, Immunogenicity

\footnotetext{
* Correspondence: zhanggaip@126.com

${ }^{+}$Chang Liu and Yunchao Liu contributed equally to this work.

${ }^{1}$ Key Laboratory of Animal Immunology of the Ministry of Agriculture, Henan

Provincial Key Laboratory of Animal Immunology, Henan Academy of

Agricultural Sciences, Zhengzhou 450002, Henan, China

${ }^{2}$ College of Animal Science and Veterinary Medicine, Henan Agricultural

University, Zhengzhou 450002, Henan, China

Full list of author information is available at the end of the article
}

(c) The Author(s). 2020 Open Access This article is licensed under a Creative Commons Attribution 4.0 International License, which permits use, sharing, adaptation, distribution and reproduction in any medium or format, as long as you give appropriate credit to the original author(s) and the source, provide a link to the Creative Commons licence, and indicate if changes were made. The images or other third party material in this article are included in the article's Creative Commons licence, unless indicated otherwise in a credit line to the material. If material is not included in the article's Creative Commons licence and your intended use is not permitted by statutory regulation or exceeds the permitted use, you will need to obtain permission directly from the copyright holder. To view a copy of this licence, visit http://creativecommons.org/licenses/by/4.0/ The Creative Commons Public Domain Dedication waiver (http://creativecommons.org/publicdomain/zero/1.0/) applies to the data made available in this article, unless otherwise stated in a credit line to the data. 


\section{Background}

Porcine circovirus (PCV) is a circular single-stranded DNA virus belonging to the family Circoviridae [1]. There are three major genotypes of PCV, namely PCV1, PCV2, and PCV3. PCV1 is nonpathogenic [2], and PCV2 is associated with several diseases, collectively named as porcine circovirus associated disease (PCVAD), which causes reproductive failure and huge economic losses all over the world [3]. PCV3 is a recently identified circovirus that induces cardiac pathology and multi-systemic inflammation [4]. In April 2019, a new circovirus with a distinct relationship to other circoviruses was found in Hunan Province, China and designated as PCV4 (doi: https://doi.org/10.1111/TBED.13446). At present, at least five commercial vaccines have been licensed, including the Circovac ${ }^{\circ}$ vaccine (Merial), Ingelvac CircoFLEX $^{\odot}$ (Boehringer Ingelheim), Circumvent ${ }^{\bullet}$ (Intervet/ Merck), Porcilis ${ }^{\circ}$ PCV (Schering-Plough/Merck), as well as Fostera ${ }^{\text {ma }}$ PCV (Pfizer Animal Health Inc.) [5]. It has been reported that all the commercial vaccines were able to reduce clinical symptoms and improve reproduction to some extent in PCV2 positive farms, while they failed to eradicate this virus from farms [6, 7]. As PCV2 infection may initiate immunosuppression and also cause subsequent failure of the immune response in pigs [8], thus, a more effective vaccine should be developed to prevent PCV2 infections in swine herds. The BALB/c mouse is one of the animal models, as it has a clear background and frees from external interference, it is the most extensively used in PCV2 inactivated or subunit vaccine researches $[9,10]$.

The genome of PCV2 consists of two major open reading frames (ORFs): ORF1 and ORF2. ORF1 encodes two viral replication-associated proteins, Rep and Rep' [11]; ORF2 encodes a capsid protein (Cap), which is the primary immunogenic protein of PCV2. Cap contains critical epitopes for inducing a protective immune response, so it has been used as the target for vaccine development [12]. The Cap protein has been expressed in multiple protein expression systems (e.g., insects, mammalian, yeast, and $E$. coli cells) $[13,14]$ in vitro, whereas only baculovirus insect expression system generates two commercially available PCV2 vaccines [6]. However, low yield and high cost still exist for large scale preparation. Compared with insect expression, Escherichia coli (E.coli) is an efficient prokaryotic expression system as many significant benefits in terms of low cost, ease-of-use and scale preparation.

Generally, immunogenic protein with high-molecularweight can induce stronger immune response than lowmolecular-weight protein [15]. Calreticulin (CRT) is a highly conserved endoplasmic reticulum luminal $\mathrm{Ca}^{2+}$ binding protein and found to be involved in cellular processes (e.g., calcium storage and chaperone function) [16]. Numerous studies primarily focused on its roles in protein folding and polymerization $[17,18]$. Recombinant truncated CRT in polymers, as compared with monomers, can induce higher level of immune response [18]. Furthermore, CRT fused foreign proteins also formed into polymers and showed excellent immunogenicity of the foreign proteins [19]. In the present study, high-yield Cap-CRT fusion protein was expressed in E.coli, and the recombinant protein, rP5F could form into immunogenic polymers. Mice immunized with rP5F efficiently mounted humoral and cellular immune responses, and decrease the infection rate against PCV2-challenge, suggesting that $\mathrm{rF5}$ P could be a potential subunit vaccine candidate.

\section{Result}

Expression of cap-CRT fusion proteins and purification of rF5P

The Cap-CRT fusion proteins ( $\mathrm{rP} 4 \mathrm{C}, \mathrm{rC} 4 \mathrm{P}, \mathrm{rP} 5 \mathrm{~F}$ and rF5P) were successfully expressed in E. coli, whereas all of them led to inclusion bodies (IBs) at $37^{\circ} \mathrm{C}$ (Fig. 1b) (Supplementary Material Original Fig. 1b). SDS-PAGE indicated that only rF5P achieving soluble expression with a molecular mass of $48 \mathrm{kDa}$ at low temperature $\left(25^{\circ} \mathrm{C}\right)$ for $16 \mathrm{~h}$ (Fig. 2a lane 1). After rF5P was purified by Ni-NTA affinity chromatography, its quality was nearly $0.5 \mathrm{mg} / \mathrm{mL}$ with a purity of about $90 \%$ (Fig. 2a lane 4) (Supplementary Material Original Fig. 2a).

The purified rF5P by Ni-NTA was eluted from the Superdex $200 \mathrm{pg}(26 / 60)$ gel filtration column. The target protein was presented as the first and highest peak, which beyond the detection limit of the column, suggesting that rF5P could form high-molecular-weight polymers (Fig. 2c lane 5). Besides, enrichment was also detected after elution from the column as the quality of rF5P was about $0.65 \mathrm{mg} / \mathrm{mL}$ (Fig. 2a, c lane 5). The results of Western Blot suggested that $\mathrm{rF5P}$ reacted specifically with anti-His mAbs (Fig. 2b) (Supplementary Material Original Fig. 2b). The third peak also recognized anti-His mAbs, revealing that only a small fraction of rF5P might exist in the form of monomer (Fig. 2b, c lane 6).

\section{Characterization of rF5P}

To examine the morphology of high-molecular-weight polymers, the purified rF5P was analyzed under a TEM. The observed result revealed that $\mathrm{rF5}$ P was assembled into a spheroidal particle with a diameter of $30 \mathrm{~nm}$, whereas the size distribution of the particles was not exactly the same, as shown in Fig. 3a, suggesting that there might be some incompletely assembled protein fragments. The DLS result indicated that the average hydrodynamic diameter of rF5P was about $100 \mathrm{~nm}$ (Fig. 3b). The sizes of rF5P particles observed using the two methods were not consistent, probably attributed to the hydration radius detected by DLS was larger than the theoretical or real value. 


\begin{tabular}{|c|c|c|c|c|}
\hline Fragment rP4C & $\mathrm{BamH} 1$ & Cap & $4 \times$ GGGGS & $\begin{array}{l}\text { Calreticulin } \\
(120-250 \text { aa) }\end{array}$ \\
\hline Fragment rC4P & $\mathrm{BamH} 1$ & $\begin{array}{l}\text { Calreticulin } \\
(120-250 \text { aa })\end{array}$ & $4 \times$ GGGGS & Cap \\
\hline Fragment rP5F & $\mathrm{BamH} 1$ & Cap & $5 \times \mathrm{GGGGS}$ & $\begin{array}{l}\text { Calreticulin } \\
\text { (120-308 aa) }\end{array}$ \\
\hline Fragment rF5P & $\mathrm{BamH} 1$ & $\begin{array}{l}\text { Calreticulin } \\
(120-308 \mathrm{aa})\end{array}$ & $5 \times G G G G S$ & Cap \\
\hline
\end{tabular}

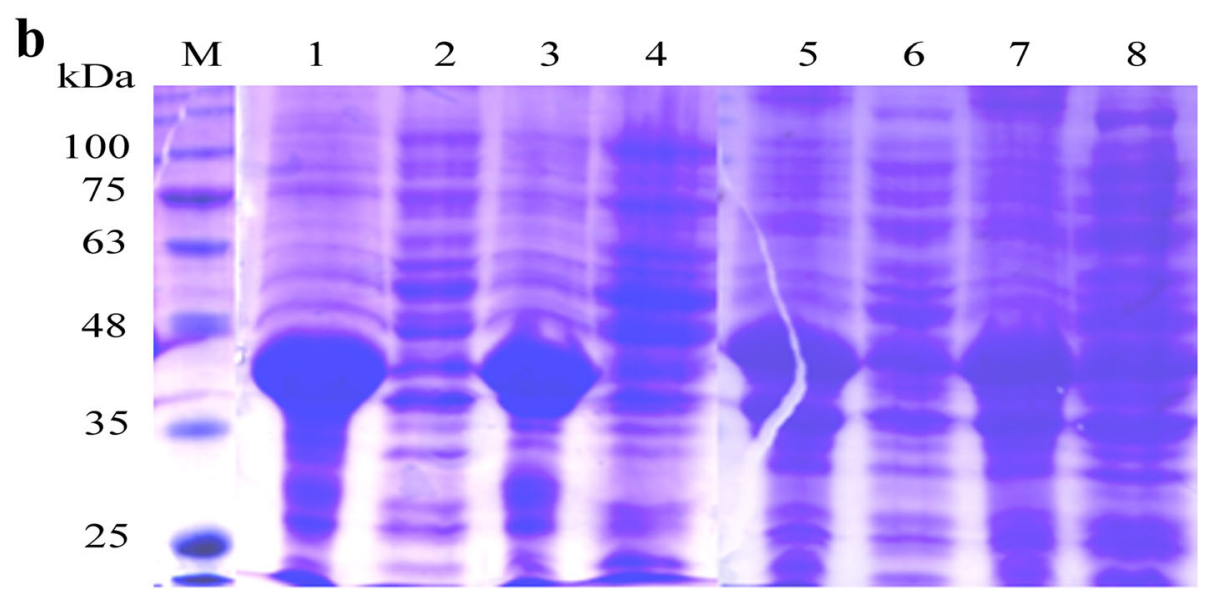

Fig. 1 The schematic structure (a) and SDS-PAGE (b) of four recombinant Cap-CRT fusion proteins. a Fragments were used for constructing the recombinant proteins. Blue squares represent completely cap of PCV2 and truncated calreticulin. GGGGS in grey are linkers between cap and calreticulin. Each fragment is encoded by BamHI and Xhol, respectively. b Solubility of rP4C, rC4P, rP5F and rF5P induced by IPTG at $37^{\circ} \mathrm{C}$. M: protein ladder; Lane 1,3,5,7: precipitate of pET-28a-rP4C/rC4P/rV5P/rF5P; Lane 2,4,6,8: supernatant of pET-28a-rP4C/rC4P/rV5P/rF5P

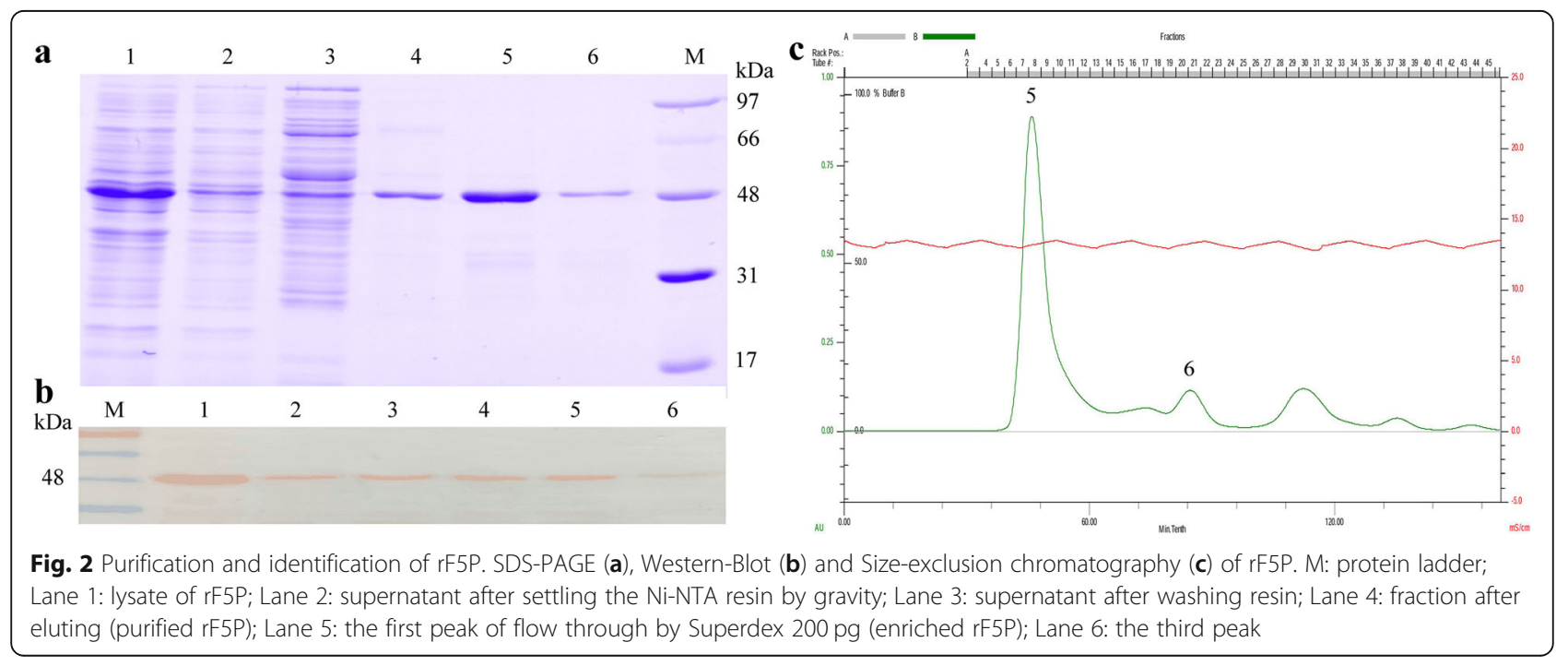



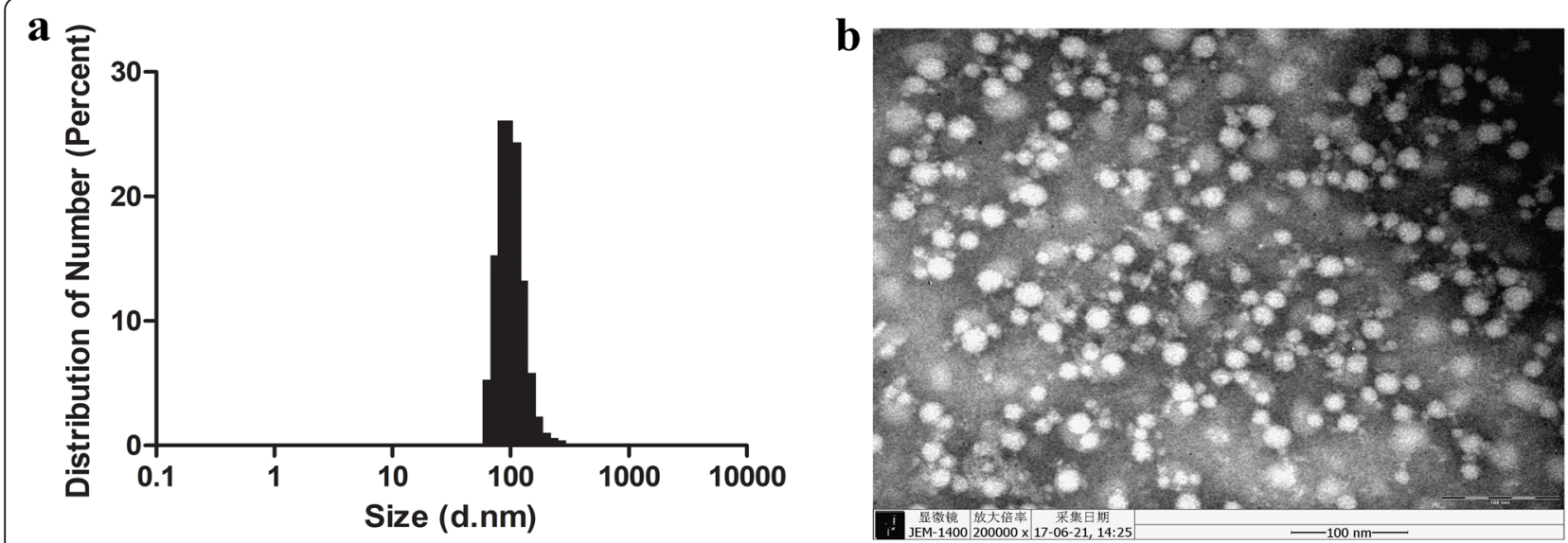

Fig. 3 Characterization of rF5P. a Negative staining electron microscopy of rF5P, bar size, $100 \mathrm{~nm}$. b Dynamic light scattering result of rF5P

The results of the antigenic analysis showed that rF5P could recognize clinical positive serum and anti-PCV2 mAbs 6A4, which indicated that rF5P had the similar characters as intact particle (Fig. 4). Compared with clinical positive serum, the mAbs $6 \mathrm{~A} 4$ showed a relative weaker ability to recognize rF5P (Fig. 4b). However, the rF5P exhibited a high background interference of clinical negative serum, which probably associated with the complexity of the field sample (Fig. 4a).

\section{PCV2-specific humoral immune response}

Indirect ELISA was performed to evaluate PCV2-specific humoral immune response induced by $\mathrm{rF5P}$ in mice. Figure 5a shows that compared with the PBS group, PCV2-specific antibodies appeared at $21 \mathrm{dpi}$ in all groups and increased with the advancement of the immune process. The antibody levels of MLY and BLG groups were overall higher than those of $\mathrm{rF} 5 \mathrm{PH}$ and rF5PL groups before virus challenging, but the contrary phenomenon happened after that. During the entire immune process, the levels of rF5PH group were higher than those of the rF5PL group, whereas there was no significant difference between them. No antibody was produced in the PBS group before the challenge, and the antibody level increased immediately at 7 days after challenge and reached peak at 14 days.

Whether the antibodies generated by immunized mice could neutralize the virus, NA was adopted to further detect the PCV2-specific humoral immune response. The results indicated that all immune groups produced neutralizing antibodies except the PBS group, which were consistent with the results of indirect ELISA. The NA titers of rF5PH groups were higher compared with those of MLY and BLG at 42 and 49 dpi (Fig. 5b). After the challenge, NA titers in the PBS group increased rapidly and reached 1:16 at 4 weeks. Besides, the NA level in other immune groups decreased at $63 \mathrm{dpi}$ (1 week after challenge); it returned to the level of pre-challenge at $70 \mathrm{dpi}$ and remained unchanged until the completion of the test.

\section{Lymphocyte proliferative response and cytokine assay}

Three mice in each group were sacrificed to isolate lymphocyte for lymphocyte proliferation and cytokine
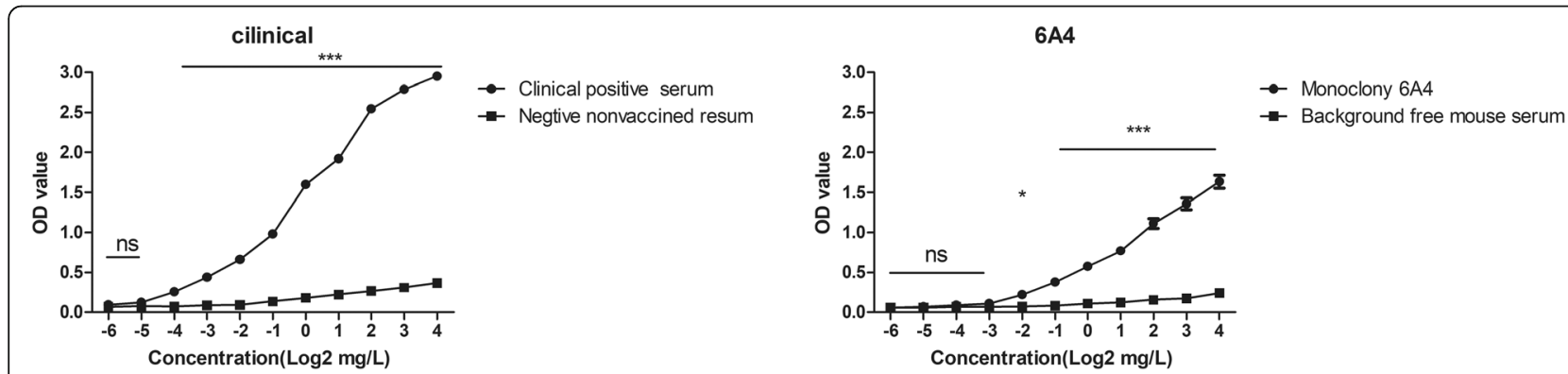

Fig. 4 Antigenic characterizations of rF5P using swine clinical positive sera (a), anti-PCV2 mAbs 6A4 (b) and anti-His mAbs (c) by ELISA, and the results are expressed as mean OD value \pm SEM, the statistical significance differences between each group was analyzed by two-way ANOVA statistical analysis, ${ }^{*} P<0.05,{ }^{* *} P<0.01,{ }^{* *} P<0.001$, ns represented not significant 

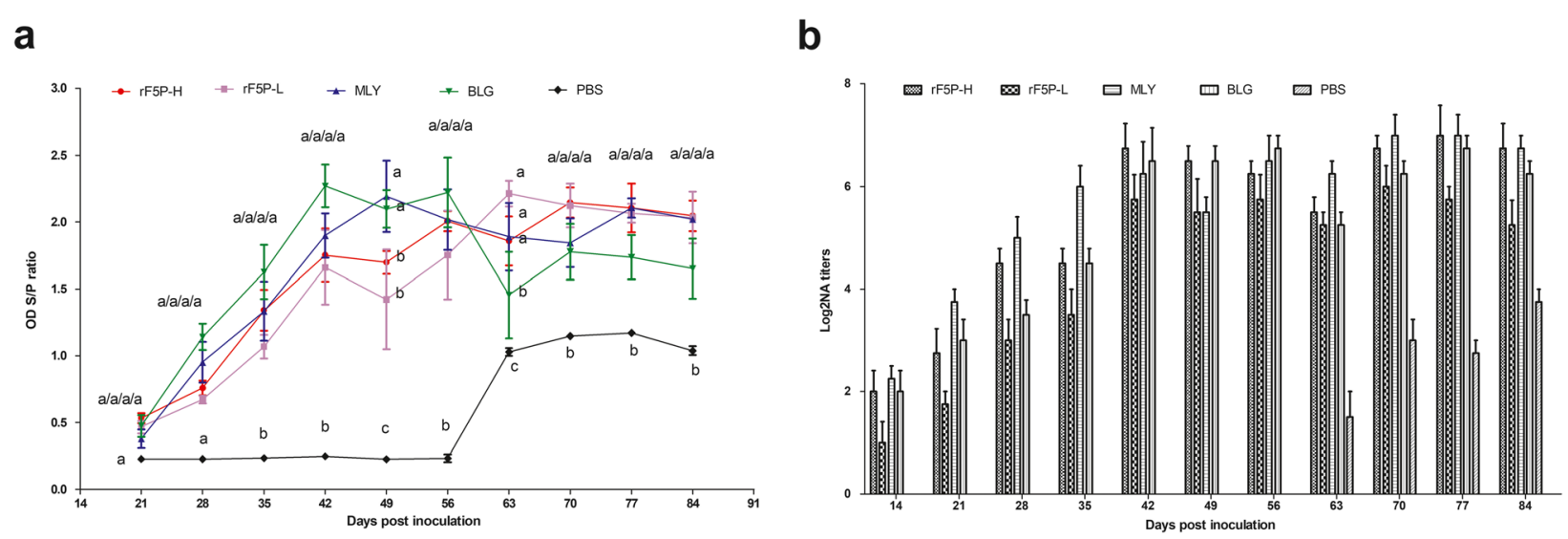

Fig. 5 Detection of PCV2-specific immune responses in mice. Groups of mice $(n=6)$ were immunized with $30 \mu g$ and $15 \mu \mathrm{g}$ of $\mathrm{rF} 5 \mathrm{P}$, commercial inactivated Circovac ${ }^{\oplus}$ vaccine (Merial), subunit vaccine Ingelvac CircoFLEX ${ }^{\circledast}$ (Boehringer Ingelheim) and PBS in injection, Blood samples were collected for PCV2-speicific IgG titers(a) and virus neutralization antibody (b). Titers of antibodies are expressed as mean \pm SEM. Different letters (a, b, and $\mathbf{c})$ indicate statistically significant difference $(P<0.05)$ among groups

quantification through PCV2 strain DF-1 stimulation. The lymphocyte proliferative responses were detected in all immunized groups aside from the mock group. The SIs of rF5PH, MLY and BLG groups were significantly higher than that of the PBS group $(P<0.01)$, and there was no significance between the four immunized groups $(P>0.05)$ (Fig. 6f). The results suggested that cytokine levels were slightly higher in all the immune groups than the mock group, whereas there was no regular correlations and significant difference in the values (Fig. 6a-e).

\section{Quantification of PCV2 in tissues}

PCV2 DNA extracted from different tissues of all experimental groups post-challenge was quantified using realtime fluorescent quantitative PCR. Figure 7 suggested that excepted kidneys, the PBS group showed a significantly higher viral load than the other groups. The amounts of virus in the spleens and lungs of the immunized groups were lower than that in the PBS group $(P<0.05)$, and it showed no difference between the immunized groups (Fig. 7c, d). The rF5P groups exhibited the highest viral loads in the livers (Fig. 7b), but the

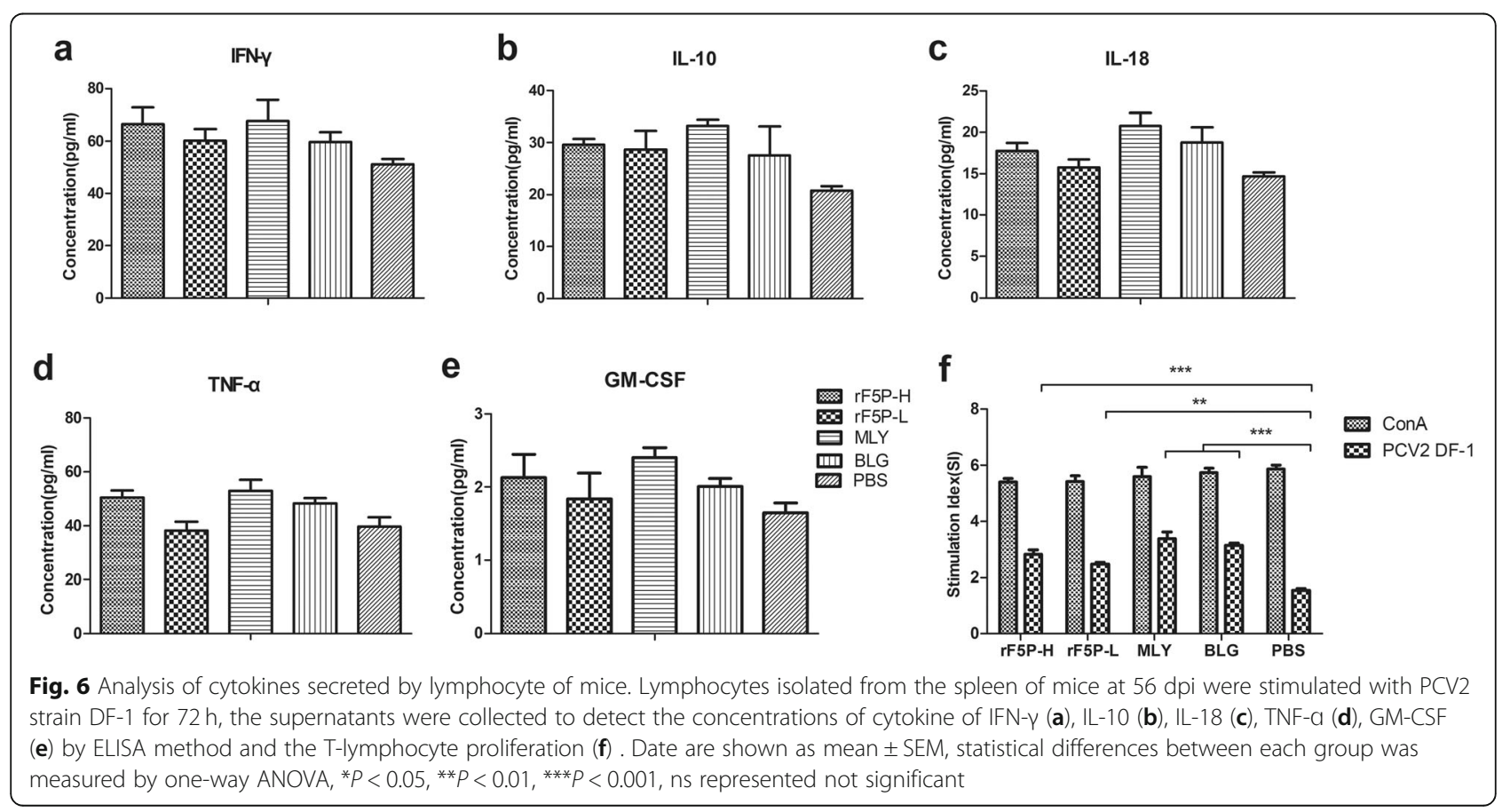




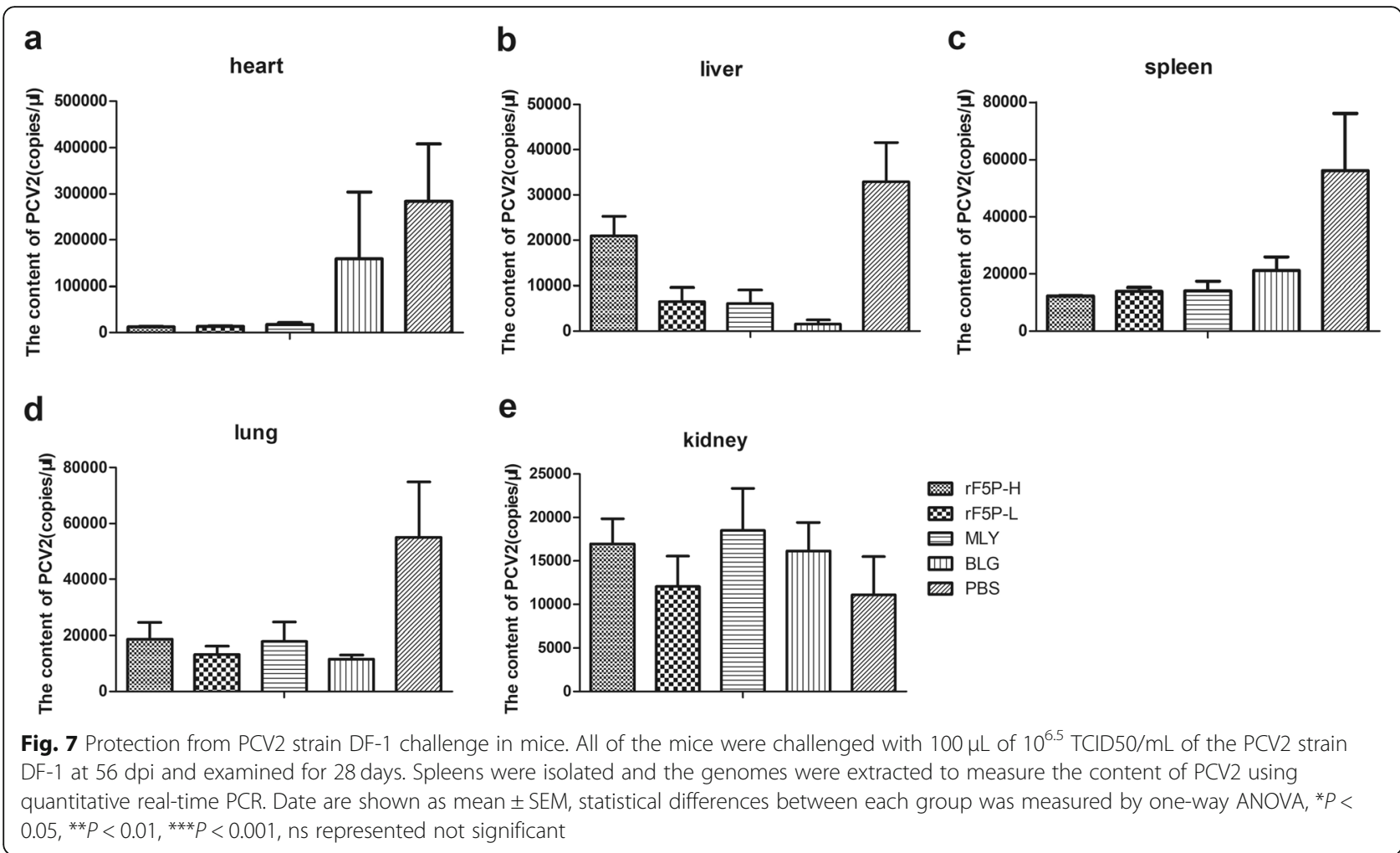

lowest in the hearts (Fig. 7a). There was no difference among all groups in the kidneys (Fig. 7e). All the results revealed that mice immunized with $\mathrm{rF5}$ P could effectively reduce viral loads in organs against the PCV2 challenge.

\section{Discussion}

PCV2, an agent of PCVDs, acts as a vital economical viral pathogen affecting the global swine industry. Vaccination has been demonstrated as a feasible means to control PCVAD. In this study, the Cap-CRT fusion proteins which could form into high immunogenic polymers were first produced in E. coli. Though there are multiple protein expression systems for protein expression in vitro, each system exhibits features and advantages, it also has limitations such as low yield and high cost which hinder the development of the recombinant protein into a truly useful vaccine. Meanwhile, E. coli prokaryotic expression system has been extensively adopted for recombinant protein production in laboratories and industry for its simplicity, rapid growth rate and relatively low cost.

Studies on Cap proteins focus on their abilities to selfassemble into virus-like particles (VLPs) and thus exert immune effects as an entire virus, which also prove that large molecular particles have stronger immune effects than monomer proteins [20]. However, the expression of recombinant proteins in E.coli often results in insoluble and/or nonfunctional IBs which may due to rapid synthesis and lack of post translational modification. CRT has been shown to be able to self-assemble effectively and acts as a chaperone to help dissolve and form the correct structure [21]. Three fourths design of CapCRT fusion proteins formed into IBs, only the rF5P transformed into soluble macromolecular particles in vitro by optimizing the expression conditions. However, the observations of TEM and DLS revealed that the particle radius was not the same, probably attributed to the DLS of hydrated radius larger than the theoretical or actual size. Besides, compared with other VLPs reports, the rF5P did not form VLPs.

The BALB/c mouse is one of the animal models, as it has a clear background and frees from external interference, it is the most extensively used in PCV2 inactivated or subunit vaccine researches $[9,10]$. Though mice may not be an ideal animal model to resemble PCV2 infection as observed for pigs, PCV2 can infect and replicate in some mouse strains including BALB/c mouse when used with the appropriate inoculating dose and administered route. In the present study, the BALB/c mouse model was used to assess the immunogenicity and protective capabilities of an experimental vaccine based on the recombinant Cap-CRT fusion protein expressed in E.coli.

The Cap-CRT fusion protein ( $\mathrm{rF5}$ ) induced production of PCV2-specific ELISA antibodies and neutralization antibody against PCV2 were detected, the PCV2-specific ELISA antibodies were positively correlated with the 
neutralization antibodies, which was consistent as described in Zhu [22]. The specific antibody levels of protein groups were lower than those of commercial vaccine groups before virus challenge, but it went opposite after the virus challenge. The neutralizing antibody levels of protein groups were slightly lower than commercial vaccine groups during the immune process. Both the protein and the commercial vaccine groups induced only part of the cellular immune response. Under the stimulation of PCV2, T lymphocytes proliferated significantly, whereas various cytokines were irregularly secreted. PCV2 infections mainly induce fetal and neonatal mortality, and the level of viruses in the tissues of PCV2 infected mice is a good indicator of the antiviral effects of any vaccine, and it primarily occurred in the lymphoid tissue and spleen [23]. After the challenge test, the viral loads in the spleens of mice in the protein and commercial inactivated vaccine group were significantly lower than those in the mock group. It was also slightly effective in the organs of the heart, liver and lung, which was not completely consistent with Wang's research, PCV2 mainly deposited in the lungs [9]. The humoral immune response showed no significant difference between protein groups and commercial vaccine groups. Overall, the humoral and cellular immune levels of rF5P groups were similar to the two types of commercial vaccine groups, and the aggregate performance of rF5P was closer to BLG subunit vaccine. Our results clearly verified that the Cap-CRT fusion protein (rF5P) elicited humoral and part of cell mediated immune responses comparable to commercial inactivated and subunit vaccines, and protected mice against epidemic PCV2 strain DF-1 challenge.

\section{Conclusions}

To sum up, this paper first describes that the PCV2 Cap protein fused with truncated calreticulin ( $\mathrm{rF5P}$ ) could be soluble expressed into immunogenically polymers in $E$. coli. Vaccination of mice elicited humoral and part of cellular immune responses comparable to the commercial inactivated and subunit vaccines, and significantly reduced the viral loads in tissues subsequent to a viral challenge. Besides, the immune effect of Cap-CRT fusion protein requires further verifications in pigs as the natural hosts of PCV2. The rF5P can potentially develop a subunit vaccine against PCV2 infection.

\section{Methods}

\section{Cells and virus}

PK-15 cells (ATCC ${ }^{\mathrm{mm}}$ CCL-33) were cultured in Dulbecco's Modified Eagle Medium (DMEM; Gibco) containing 10\% fetal bovine serum (FBS, HyClone), $100 \mathrm{IU} / \mathrm{mL}$ Penicillin and $100 \mathrm{mg} / \mathrm{L}$ Streptomycin (InvivoGen, France) at $37{ }^{\circ} \mathrm{C}$ in a $5 \% \mathrm{CO}_{2}$ atmosphere. PCV2 strain DF-1 (GenBank Accession Number: JN119255) was grown in PK-15 cells and utilized for virus neutralization assay (NA) and experimental challenge.

\section{Experimental animals}

Thirty female BALB/c mice of 4 weeks old weighing 14-18 g were chosen arbitrarily and purchased from the Experimental Animal Center of Zhengzhou University. The experimental mice were randomly separated into five groups and given 5 days to acclimate the housing environmental conditions (temperature: $22 \pm 3{ }^{\circ} \mathrm{C}$, humidity: $55 \pm 15 \%$, lighting: $12 \mathrm{~h}$ light/dark cycle). The mice were allowed free access to clean water and food. The animal experiments were carried out according to the Animal Experiment Committee of Henan Academy of Agricultural Sciences (Approval number SYXK 2014-0007). All animals received humane care in compliance with good animal practice according to the animal ethics procedures and guidelines of China. All sections of this report adhere to the ARRIVE Guidelines for reporting animal research [24].

\section{Plasmid construction}

As shown in Fig. 1a, complete Cap gene of PCV2 (GenBank Accession No. AY686763) was fused with the truncated calreticulin (120-308 aa/120-250 aa) (GenBank Accession No. EU639407) at N/C terminal using $4 \times$ GGGGS or $5 \times$ GGGGS linker. All these four recombinant fragments, named $\mathrm{rP} 4 \mathrm{C} / \mathrm{rC} 4 \mathrm{P} / \mathrm{rP} 5 \mathrm{~F} / \mathrm{rF} 5 \mathrm{P}$, were synthesized after codon optimization by Genscript. All the plasmids were inserted into pET-28a in $\mathrm{B} a m \mathrm{HI}$ and XhoI sites and then transformed into E. coli BL21 (DE3) competent cells, respectively.

\section{Protein expression and purification}

All the positive clones were cultured in Luria-Bertani (LB) medium containing $50 \mathrm{mg} / \mathrm{L}$ kanamycin and induced for protein expression with $0.1 \mathrm{mM} \mathrm{IPTG}$ at $37^{\circ} \mathrm{C}$ for $6 \mathrm{~h}$. The parameters of protein expression were optimized according to IPTG concentrations $(0.1 \mathrm{mM}, 0.2$ $\mathrm{mM})$, induction temperature and time $\left(18^{\circ} \mathrm{C}\right.$ for $24 \mathrm{~h}$, $25^{\circ} \mathrm{C}$ for $16 \mathrm{~h}$ ). Protein expression was verified by sodium dodecyl sulfate polyacrylamide gel electrophoresis (SDS-PAGE). The optimal harvest cells were suspended in lysis buffer ( $50 \mathrm{mM} \mathrm{PB}, 150 \mathrm{mM} \mathrm{NaCl}, 5 \%(w / v)$ Glycerol, 5\% (w/v) Triton X-100, 2 mM EDTA, 2 mM DTT, $\mathrm{pH} 7.0$ ) and then lysed by sonication ( 99 cycles of $2 \mathrm{~s}$ On/5 s Off, amp 25\%)). After centrifugation, the precipitation was removed and the supernatant of rF5P was purified by Ni-NTA affinity chromatography. After washing the Ni-NTA column (Invitrogen, USA) with wash buffer $(50 \mathrm{mM} \mathrm{PB}, 150 \mathrm{mM} \mathrm{NaCl}, 30 \mathrm{mM}$ imidazole, $\mathrm{pH} 7.0)$, rF5P was eluted with elution buffer (50 $\mathrm{mM} \mathrm{PB}, 150 \mathrm{mM} \mathrm{NaCl}, 250 \mathrm{mM}$ imidazole, $\mathrm{pH}$ 7.0). Protein fractions were analyzed by SDS-PAGE. 
The purified rF5P was enriched and analyzed by sizeexclusion chromatography with Superdex 200 prep grade (pg) (26/60) gel filtration column (GE Healthcare, USA). The samples were eluted using lysis buffer at a flow rate of $1 \mathrm{~mL} / \mathrm{min}$ and detected at $280 \mathrm{~nm}$ wavelength. The collected fractions were identified by SDSPAGE and Western Blot and then quantified using BCA Protein Assay Kit (TIANGEN, China).

\section{Characterization of $\mathrm{rF5P}$}

The purified rF5P was observed under a transmission electron microscopy (TEM) using the negative staining method and dynamic light scattering (DLS) according to the previous study [25].

\section{Antigenicity analysis of $\mathrm{rF} 5 \mathrm{P}$}

Indirect enzyme-linked immunosorbent assay (ELISA) was performed to test the antigenicity of rF5P with swine clinical positive/negative serum and mouse antiPCV2 monoclonal antibodies (mAbs) 6A4 (Abcam, USA). The ELISA procedure was operated as routine.

\section{Vaccination and challenge in mice}

Thirty female BALB/c mice were randomly divided into 5 groups $(n=6)$. The mice were inoculated subcutaneously with $30 \mu \mathrm{g}$ and $15 \mu \mathrm{g}$ of rF5P as Group rF5PH and Group rF5PL, respectively; $50 \mu \mathrm{L}$ of commercial inactivated Circovac $^{\circ}$ vaccine (Merial), subunit vaccine Ingelvac CircoFLEX $^{\circ}$ (Boehringer Ingelheim) and PBS were classified as positive and negative controls, named as Group MLY, BLG and PBS, respectively.

The rF5P was diluted in $50 \mu \mathrm{L}$ of PBS and then emulsified with $50 \mu \mathrm{L}$ of Complete Freund's adjuvant for the first immunization, and subsequently with $50 \mu \mathrm{L}$ of Incomplete Freund's adjuvant for booster at an interval of 4 weeks. At 56 days after the first immunization, 3 mice from each group were sacrificed for both lymphocyte proliferation assay and cytokine production. In order to reduce the pain of mice to the greatest extent, cervical dislocation was chosen to kill them. It is the fastest method to make the spinal cord and brain spinal cord disconnected, so that the central nervous system instantly lost control of the whole body, which is in line with the requirements of animal welfare. The rest alive mice received $100 \mu \mathrm{L}$ of $10^{6.5}$ $\left(\mathrm{TCID}_{50}\right) / \mathrm{mL}$ PCV2 strain DF-1, and they were monitored for the following 28 days. Next, the mice were sacrificed for PCV2 content in different organs. Blood samples were collected from the tail veins each week.

\section{Antibody response in mice}

The serum samples taken at each point post immunization were monitored for specific antibodies using Porcine circovirus type 2 ELISA antibody test kit (KeQian, China). Operation steps followed the manufacturer's instructions.

\section{Neutralization assay}

The abilities of all serum samples to neutralize the PCV2 strain DF-1 were assessed using virus NA. In brief, $50 \mu \mathrm{L}$ sera pretreated at $56^{\circ} \mathrm{C}$ for $30 \mathrm{~min}$ were diluted in a serial two-fold way from 1:2 to $1: 1024$ and mixed with an equal volume of virus (400 $\mathrm{TCID}_{50}$ ) at $37^{\circ} \mathrm{C}$ for $1 \mathrm{~h}$. The serum-virus complex was transferred into confluent PK-15 cells in each well and then incubated at $37^{\circ} \mathrm{C}$ for $72 \mathrm{~h}$. Since no visible cytopathic effect was verified, immunoperoxidase monolayer assay (IPMA) was performed to ascertain the presence of the virus [10]. Virus neutralization titer was expressed as the highest dilution as $\log _{2} \mathrm{NA}$ in which no higher than $80 \%$ reduction of virus replication was detected as compared with the virus control.

\section{Spleen lymphocyte proliferation assay}

Spleens of mice from each group were removed at 56 days post inoculation (dpi). The spleen lymphocytes were isolated by Lydroxypropylmethyl Cellulose (Solarbio, China) and then resuspended in RPMI 1640 medium containing $10 \%$ FBS. Lymphocyte proliferation assay was performed by cell counting kit-8 assay (Beyotime Biotechnology, China) as previously described [26]. T lymphocyte proliferation was represented as the stimulation index (SI), the ratio of the mean reading of stimulated wells to unstimulated ones.

\section{Analysis of cytokine production by activated lymphocytes The supernatants from the spleen lymphocytes employed in the proliferation assay were removed and adopted to analyze cytokines. The assays were per- formed using commercially available mice IFN- $\gamma$, IL-10, IL-18, TNF-a and GM-CSF ELISA kits (USCN Life Sci- ence, China) following the manufacturer's instructions.}

\section{Determination of PCV2 in tissue}

PCV2 DNA from different organs (heart, liver, spleen, lung and kidney) of all groups at 28 days post-challenge was quantified by real-time fluorescent quantitative PCR as previously described [27]. The viral load was calculated according to the standard curve plotting $\mathrm{Ct}$ values against different dilutions of a standard plasmid.

\section{Statistical analyses}

GraphPad Prism version 5.00 (USA) analysis of variance (ANOVA) was performed. The data is expressed as the mean \pm SEM. Statistical significance was found by two-way or one-way ANOVA at" $P<0.05,{ }^{* * *} P<0.01$, **** $P<0.001$; ns represents no statistical significance. All the experimenters were not blinded to any stage of the experiment.

\section{Supplementary information}

Supplementary information accompanies this paper at https://doi.org/10. 1186/s12917-020-02527-9.

Additional file 1. 


\section{Additional file 2}

Additional file 3.

\section{Abbreviations}

PCV2: Porcine circovirus type 2; PCVDs: Porcine circovirus diseases; PCVA D: Porcine circovirus associated diseases; Cap: Capsid protein; ORFs: Major open reading frames; CRT: Calreticulin; E.coli: Escherichia coli; IBs: Inclusion bodies; SDS-PAGE: Sodium dodecyl sulfate-polyacrylamide gel electrophoresis; ELISA: Indirect enzyme-linked immunosorbent assay; DLS: Dynamic light scattering; TEM: Transmission electron microscopy; MAbs: Monoclonal antibodies; IPMA: Immunoperoxidase monolayer assay; NA: Neutralization assay; Dpi: Days post inoculation; SI: Stimulation index; RT-PCR: Real-time PCR; IL: Interleukin; TNF: Tumor necrosis factor; IFN: Interferon; GMCSF: Granulocyte-macrophage colony stimulating factor

\section{Acknowledgments}

We thank Dr. Yinbiao Wang at Xinxiang Medical College for English writing help. We thank Dr. Shujun Chai at Henan Academy of Agricultural Sciences for providing high-level quality of animal care. We thank Dr. Hongying Chen, and Mr. Guanpeng Guo for their assistance in obtaining the PCV2 isolates DF-1 from the Henan Agricultural University.

\section{Authors' contributions}

$\mathrm{CL}, \mathrm{YL}, \mathrm{HF}, \mathrm{RD}$ and $\mathrm{GZ}$ designed the study, participated in all tests and drafted the manuscript. CL, BZ, PW and YC participated in collecting and testing samples. $\mathrm{CL}, \mathrm{YL}, \mathrm{HF}, \mathrm{HH}$ and $\mathrm{GZ}$ analyzed the data and revised the manuscript. All authors reviewed the results and approved the final version of the manuscript.

\section{Funding}

We are grateful to the financial support from three fund projects. National Key Research and Development Program of China (2017YFD0501103) supported the design of study and data collection and writing the manuscript; Key Scientific and Technological Research Projects in Henan Province (182102110087) and Scientific and Technological Projects for Overseas Students (22991803) supported analysis, interpretation of data.

\section{Availability of data and materials}

The datasets used and/or analyzed during the current study are available from the corresponding author on reasonable request.

\section{Ethics approval and consent to participate}

The animal experiments were carried out and approved by the Animal Experiment Committee of Henan Academy of Agricultural Sciences (Approval number SYXK 2014-0007). All animals received humane care in compliance with good animal practice according to the animal ethics procedures and guidelines of China.

\section{Consent for publication}

$$
\text { Not applicable. }
$$

\section{Competing interests}

The authors declare that they have no competing interests.

\section{Author details}

'Key Laboratory of Animal Immunology of the Ministry of Agriculture, Henan Provincial Key Laboratory of Animal Immunology, Henan Academy of Agricultural Sciences, Zhengzhou 450002, Henan, China. ${ }^{2}$ College of Animal Science and Veterinary Medicine, Henan Agricultural University, Zhengzhou 450002, Henan, China. ${ }^{3}$ School of Life Sciences, Zhengzhou University, Zhengzhou 450001, China.

\section{Received: 5 August 2019 Accepted: 18 August 2020}

Published online: 27 August 2020

\section{References}

1. Allan GM, Ellis JA. Porcine circoviruses: a review. J Vet Diagn Investig. 2000; 12(1):3-14.

2. Tischer I, Mields W, Wolff D, Vagt M, Griem W. Studies on epidemiology and pathogenicity of porcine circovirus. Arch Virol. 1986;91(3-4):271-6.
3. Opriessnig T, Meng XJ, Halbur PG. Porcine circovirus type 2 associated disease: update on current terminology, clinical manifestations, pathogenesis, diagnosis, and intervention strategies. J Vet Diagn Investig. 2007;19(6):591-615.

4. Phan TG, Giannitti F, Rossow S, Marthaler D, Knutson TP, Li L, Deng X, Resende T, Vannucci F, Delwart E. Detection of a novel circovirus PCV3 in pigs with cardiac and multi-systemic inflammation. Virol J. 2016;13(1):184.

5. Chae C. Commercial porcine circovirus type 2 vaccines: efficacy and clinical application. Vet J. 2012;194(2):151-7.

6. Afghah Z, Webb B, Meng XJ, Ramamoorthy S. Ten years of PCV2 vaccines and vaccination: is eradication a possibility? Vet Microbiol. 2017;206:21-8.

7. Feng H, Blanco G, Segalés J, Sibila M. Can porcine circovirus type 2 (PCV2) infection be eradicated by mass vaccination? Vet Microbiol. 2014.

8. Meng XJ. Porcine circovirus type 2 (PCV2): pathogenesis and interaction with the immune system. Annu Rev Anim Biosci. 2013;1:43-64.

9. Wang YP, Liu D, Guo LJ, Tang QH, Wei YW, Wu HL, Liu JB, Li SB, Huang LP, Liu CM. Enhanced protective immune response to PCV2 subunit vaccine by co-administration of recombinant porcine IFN-gamma in mice. Vaccine. 2013;31(5):833-8.

10. Liu C, Liu Y, Chen H, Feng H, Chen Y, Wang Y, Wang J, Liu D, Deng R, Zhang G. Genetic and immunogenicity analysis of porcine circovirus type 2 strains isolated in Central China. Arch Virol. 2018;163(4):937-46.

11. Cheung AK. Identification of the essential and non-essential transcription units for protein synthesis, DNA replication and infectious virus production of porcine circovirus type 1. Arch Virol. 2004;149(5):975-88.

12. Nawagitgul P, Morozov I, Bolin SR, Harms PA, Sorden SD, Paul PS. Open reading frame 2 of porcine circovirus type 2 encodes a major capsid protein. J Gen Virol. 2000;81(Pt 9):2281-7.

13. Lin HX, Ma Z, Fan HJ, Lu CP. Construction and immunogenicity of recombinant swinepox virus expressing capsid protein of PCV2. Vaccine. 2012;30(44):6307-13

14. Li PC, Qiao XW, Zheng QS, Hou JB. Immunogenicity and immunoprotection of porcine circovirus type 2 (PCV2) cap protein displayed by Lactococcus lactis. Vaccine. 2016;34(5):696-702.

15. Xu F, Wang Y, Tao T, Song D, Liu X. Calreticulin attenuated microwave radiation-induced human microvascular endothelial cell injury through promoting actin acetylation and polymerization. Cell Stress Chaperones. 2017;22(1):87-97.

16. Michalak M, Corbett EF, Mesaeli N, Nakamura K, Opas M. Calreticulin: one protein, one gene, many functions. Biochem J. 1999;344(Pt 2):281-92.

17. Hong C, Qiu X, Li Y, Huang Q, Zhong Z, Zhang Y, Liu X, Sun L, Lv P, Gao $X M$. Functional analysis of recombinant calreticulin fragment 39-272: implications for immunobiological activities of calreticulin in health and disease. J Immunol. 2010;185(8):4561-9.

18. Huang SH, Zhao LX, Hong C, Duo CC, Guo BN, Zhang $\amalg$, Gong Z, Xiong SD, Gong FY, Gao XM. Self-oligomerization is essential for enhanced immunological activities of soluble recombinant calreticulin. PLoS One. 2013;8(6):e64951.

19. Qiu X, Hong C, Li Y, Bao W, Gao XM. Calreticulin as a hydrophilic chimeric molecular adjuvant enhances $\lg \mathrm{G}$ responses to the spike protein of severe acute respiratory syndrome coronavirus. Microbiol Immunol. 2012;56(8):554-61.

20. Xi X, Mo X, Xiao Y, Yin B, Lv C, Wang Y, Sun Z, Yang Q, Yao Y, Xuan Y, et al. Production of Escherichia coli-based virus-like particle vaccine against porcine circovirus type 2 challenge in piglets: structure characterization and protective efficacy validation. J Biotechnol. 2016;223:8-12.

21. Shiraishi N, Inai Y, Hirano Y, Ihara Y. Calreticulin inhibits prion protein PrP(23-98) aggregation in vitro. Biosci Biotechnol Biochem. 2011;75(8):1625-7.

22. Zhu X, Liu J, Bai J, Liu P, Zhang T, Jiang P, Wang X. Baculovirus expression of the Nterminus of porcine heat shock protein Gp96 improves the immunogenicity of recombinant PCV2 capsid protein. J Virol Methods. 2016;230:36-44.

23. Becskei Z, Aleksic-Kovacevic S, Rusvai M, Balka G, Jakab C, Petrovic T, Knezevic M. Distribution of porcine circovirus 2 cap antigen in the lymphoid tissue of pigs affected by postweaning multisystemic wasting syndrome. Acta Vet Hung. 2010;58(4):483-98.

24. Kilkenny C, Browne WJ, Cuthill IC, Emerson M, Altman DG. Improving bioscience research reporting: the ARRIVE guidelines for reporting animal research. J Pharmacol Pharmacother. 2010;1(2):94-9.

25. Ding $P$, Zhang T, Li Y, Teng M, Sun Y, Liu X, Chai S, Zhou E, Jin Q, Zhang G. Nanoparticle orientationally displayed antigen epitopes improve neutralizing antibody level in a model of porcine circovirus type 2. Int J Nanomedicine. 2017;12:5239-54. 
26. Ji P, Liu Y, Chen Y, Wang A, Jiang D, Zhao B, Wang J, Chai S, Zhou E, Zhang G. Porcine parvovirus capsid protein expressed in Escherichia coli selfassembles into virus-like particles with high immunogenicity in mice and Guinea pigs. Antivir Res. 2017;139:146-52

27. Li J, Shi JL, Wu XY, Cong XY, Xu SJ, Yuan XY, Wu JQ, Sun WB, Du YJ, Peng Z, et al. Differentiation of PCV1 and PCV2 by a multiplex real-time PCR assay. Vet Rec. 2013;173(14):346.

\section{Publisher's Note}

Springer Nature remains neutral with regard to jurisdictional claims in published maps and institutional affiliations.

Ready to submit your research? Choose BMC and benefit from:

- fast, convenient online submission

- thorough peer review by experienced researchers in your field

- rapid publication on acceptance

- support for research data, including large and complex data types

- gold Open Access which fosters wider collaboration and increased citations

- maximum visibility for your research: over $100 \mathrm{M}$ website views per year

At $B M C$, research is always in progress.

Learn more biomedcentral.com/submissions 